\title{
A simple approach to overcome the problems arising from the Keynesian stability condition
}

\author{
Reiner Franke* \\ University of Kiel, Germany
}

The Keynesian stability condition is a necessary assumption for the IS equilibrium concept to make economic sense. With reasonable values for the saving parameter(s), however, it typically implies excessively strong multiplier effects. This is more than a cosmetic issue, not least because any simulation study of an otherwise ambitious model will thus be franght with severe problems along some of its dimensions. The present paper demonstrates that by introducing proportional tax rates on production, corporate income and personal income, the multipliers will be considerably dampened. Within an elementary Kaleckian framework, it also advances a fairly satisfactory numerical calibration.

Keywords: investment multiplier, proportional taxes, public debt, functional finance, moment matching

JEL codes: $C 02, D 84, E 12, E 30$

\section{INTRODUCTION}

It is a convenient practice in post-Keynesian structuralist modelling to employ the device of continuous goods market clearing. For the instantaneous output adjustments and their implications to make economic sense, it is then necessary to assume that the sensitivity of investment to changes in utilization is lower than the utilization sensitivity of aggregate saving. This requirement is usually referred to as the Keynesian stability condition.

Although the condition is universally applied, it is not without problems. With ordinary saving functions it is well-known that reasonable values of their parameter(s) cause excessively strong reactions of IS utilization to changes in the variables of the model or some of the parameters. This feature could perhaps be neglected as long as the models remain relatively simple and one is only interested in the sign of the reactions. However, when the models become more complex and thus numerical simulations can no longer be avoided, the strong multiplier effects are rather awkward and can also easily give rise to misleading conclusions.

In this situation most of the literature simply chooses to accept the disproportions among some of the model's variables, apparently hoping that the essential properties of the model do not suffer too much from them. Alternatively, one way out is the specification of a more

* Email: franke@uni-bremen.de. Detailed and helpful comments by two anonymous referees are gratefully acknowledged.

Received 13 December 2015, accepted 12 July 2016 
elaborated saving behaviour with dynamic elements. ${ }^{1}$ While this is important work and will introduce a more realistic flavour, it has the disadvantage that it loses contact with the elementary modelling of the profession and the economic wisdom established there. The present contribution therefore proposes a less radical way. It starts out from a canonical Kaleckian macro model, for concreteness, and augments it by a government sector where, in particular, it advances proportional tax rates on different income sources. The central point of this approach is that the corresponding modifications of aggregate demand will weaken the original reactions of the IS utilization rate. This finding leads us then to a numerical issue, namely whether the dampening of the multiplier effects could also be quantitatively significant.

Besides, sooner or later the baseline models need to take government activities into account, even if they follow rigid rules, and then taxes will have to be introduced anyway.

The paper is organized as follows. Section 2 starts out from the canonical Kaleckian model and recapitulates the problems that the Keynesian stability condition poses at various methodological levels. Section 3 introduces the government sector with its expenditures on the one hand, and the tax collections from production, corporate income and personal income on the other. It is then easily seen that the income effects of the latter alleviate the IS equilibrium reactions.

As the government budget will generally not be balanced, our extension implies changes in the bonds that the government issues to finance its deficit. The financing of private investment is also included in the model, though in a most simple way. Section 4 makes these dynamic elements explicit and studies the steady-state positions that are constituted by the synchronous growth of the capital stock and the stocks of public and private debt. Against this background, Section 5 turns to a quantitative assessment of the IS multiplier effects. On the basis of some empirical key rates and ratios, it investigates how close the model can come to the empirical tax-to-GDP ratio and a proxy for the investment multiplier. Section 6 briefly sketches possible improvements upon such an attempt at a calibration and Section 7 concludes. Some details regarding mathematics and data issues are relegated to Appendix 1.

\section{THE KEYNESIAN STABILITY CONDITION AND ITS PROBLEMS IN THE SHORT AND LONG PERIOD}

To set the stage, consider the canonical Kaleckian growth model (Lavoie 2014: sec. 6.2.1) of a closed one-good economy without a public sector and without financial constraints, where technical change is Harrod-neutral and labour is in perfectly elastic supply:

$$
\begin{gathered}
r=b u-\delta \\
g^{s}=s_{r} r \\
g^{i}=g^{*}+\beta\left(u-u_{d}\right) \\
g^{i}=g^{s} .
\end{gathered}
$$

1. Some references will be given in Section 2 below. A different direction yet was chosen in a number of papers and books by the so-called 'Bielefeld School' (for example, Chiarella et al. 2005; the expression itself was coined by J. Barkley Rosser, see ibid.: xv). This approach abandons IS altogether, which for consistency requires the introduction of inventories and thus a rule for inventory investment (with Metzler as its patron saint). A problem with this treatment, then, is that the inventory accelerator can interfere with other dynamic effects that may be felt to be more important. 
The first equation introduces the rate of profit, $r$. It is basically determined by the product of the share of profits in total income, $h$, and the output-capital ratio $u$, while the rate $\delta$ nets outs capital depreciation. The output-capital ratio will also be referred to as (capital) utilization.

The function $g^{s}$ in (2) represents the aggregate saving in the economy, normalized by the (replacement value of the) capital stock: workers consume all of their wages, the profits of the firms are completely paid out to the shareholders, and $s_{r}$ is the propensity to save out of this rentier income. The third equation specifies the investment function of the firms, that is, the planned growth rate of the capital stock, which is based on a trend rate of growth $g^{*}$ as it is currently perceived by the managers. ${ }^{2}$ The second term in (3) refers to a 'normal' or desired rate of utilization $u_{d}$. This concept admits of overutilization, when $u>u_{d}$, and says that in such a situation the firms seek to reduce this gap by increasing the capital stock at a higher rate than $g^{*}$, and correspondingly for underutilization, when $u<u_{d}$. For our present purpose it is useful to treat the profit share $h$, the trend growth rate $g^{*}$ and desired utilization $u_{d}$ as exogenously fixed parameters.

Equation (4) postulates goods market equilibrium. The market clearing is brought about by quantity variations, from which the rate of utilization results as

$$
u=\frac{g^{*}+s_{r} \delta-\beta u_{d}}{s_{r} h-\beta} .
$$

With more elaborated investment functions than (3), some other dynamic variables may additionally show up in the numerator, where we are especially thinking of the ratios of financial assets to the capital stock. This notwithstanding, stability of the quantity adjustment process requires the denominator of (5) to be positive, that is, investment must be less sensitive to changes in utilization than saving:

$$
\beta<s_{r} h \text {. }
$$

This is the well-known Keynesian stability condition. It also means that the multiplier works out in the correct direction: for example, ceteris paribus utilization will rise when the firms expect a higher trend growth rate $g^{*}$ and therefore increase their investment demand. Besides, with (6) the much celebrated paradox of thrift obtains according to which a higher saving propensity reduces rather than stimulates economic activity.

The Keynesian stability condition might be accepted if equations (1)-(4) were regarded as a description for the short period. Following Skott's (2012:134) argument in a discretetime setting, the investment function includes several lags and in the short period these effects can be thought of as being part of a constant term like $g^{*}$. The remaining reactions to the contemporaneous utilization rate could thus be rather weak.

A more serious issue is the assumption in the Kaleckian approach that the short-run condition applies in the long run as well. Hence there would be no real loss in using a static specification of the investment function, as in equation (3), for this time frame. The elimination of lags and explicit dynamics only serves to simplify the analysis and to provide a convenient platform for extensions in various directions (cf. Skott 2012: 134). In this case it has, however, to be taken into account that the coefficient $\beta$ sums up the reactions to all of the lagged utilization rates. As a consequence, it is then no longer obvious that such a modified coefficient $\beta$ will still be less than $s_{r} h$. Skott (2012) develops this argument in greater detail (with a slightly different saving function) and concludes that even an a priori reasoning and a sketchy empirical analysis fail to produce any

2. Such a term is also often dubbed the firms' 'animal spirits'. 
evidence for a sufficiently weak responsiveness of investment to utilization. Similar assessments can also be found elsewhere in the literature (Dallery 2007: sec. IV; or Lavoie 2010: 136).

Postulating multiple lags in a functional relationship is a straightforward econometric approach to filter out from the data the reactions of the firms in a changing environment. It can thus give some hints to the specification of dynamic adjustments in a small-scale model, but as a stylized behavioural description of the firms' investment it is less convincing. The short period can, however, be readily and consistently linked to the long period, and high values of $\beta$ be maintained in the investment function, if $g^{i}$ in (3) is regarded as an investment rule that the firms would follow under stable circumstances. In the presence of short-run fluctuations, on the other hand, current investment will generally deviate from this level. The point is that the firms perceive this as a disequilibrium situation and that they, realistically, seek to close the gap between their current and desired investment not instantaneously but in a gradual procedure.

Accordingly, let us treat the capital growth rate $g$ as a variable that is predetermined within the short period and suppose sluggish adjustments of $g$ towards $g^{i}$. Substituting (1) in (2) and writing the saving function as $g^{s}=g^{s}(u)$, the temporary IS equilibrium condition reads $g=g^{s}(u)$ and utilization is given as a function of the current capital growth rate,

$$
u=u(g)=\frac{g+s_{r} \delta}{s_{r} h} .
$$

The capital growth rate is a dynamic variable that changes over time. With an adjustment speed $\lambda>0$ and working in continuous time, its motions are governed by the adjustment equation

$$
\dot{g}=\lambda\left\{g^{i}[u(g)]-g\right\}
$$

where for the sake of the argument the trend growth rate $g^{*}$ in the investment function (3) continues to be fixed. ${ }^{3}$ Incidentally, a dynamic model like (7), (8) may be viewed as a Kaleckian model of an earlier generation. Rather than the level of investment, it considers it more appropriate to specify the change in investment as the relevant endogenous variable. In fact, this idea is often attributed to Steindl (1952). The common alternative nowadays that makes $g$ (rather than $\dot{g}$ ) a function of utilization (and perhaps other variables) can be said to have started later with, in particular, the contributions by Rowthorn (1981), Dutt (1984), Bhaduri/Marglin (1990). ${ }^{4}$

By construction, the Keynesian stability condition poses no problem for the short-run utilization in equation (7). The condition nevertheless raises its head when it comes to the stability of the long-run dynamics. Equation (8) constitutes a one-dimensional differential equation (8) in $g$, and it is easily checked that its derivative with respect to $g$ is negative and therefore stability prevails if, and only if, inequality (6) holds true again.

There seems to be a tendency to believe that stability is required for a model to be economically meaningful, and for its steady state to be empirically relevant. However, in general this is an unnecessarily strong point of view. ${ }^{5}$ For one thing, global divergence can be avoided if one or two suitable nonlinearities are introduced into the model. Second and

3. An assumption that $g^{*}$ directly or indirectly increases when utilization $u$ increases would introduce a Harrodian, that is, destabilizing mechanism.

4. This is not to say that a formulation like (8) has been completely forgotten. A recent example is Assous/Dutt (2013: 1410); an older one Jarsulic (1992: 320).

5. The following reasoning joins Skott (2010: 115), to name just one explicit reference. 
equally importantly, an unstable steady-state growth path does not need to lose its explanatory power as it is consistent with endogenously generated, bounded fluctuations around it. That is, the steady state is locally repelling, as in the original setting, while some stabilizing forces become dominant in the outer regions of the state space. The steady-state solution may then still provide a good approximation of the medium-run time averages of the global dynamics.

Although these arguments may be accepted in general, they do not solve all of the problems. To begin with, observe that utilization in the steady state of system (7), (8) is also given by equation (5). ${ }^{6}$ Hence a violation of the Keynesian stability condition would imply that a higher trend growth rate $g^{*}$ lowers the utilization rate in the new steady state (where, in line with 'Kaleckian' theory as it is presently often understood, actual and desired utilization may differ). By the same token, the paradox of thrift would fail to apply. As these conclusions (or at least the first one) do not appear acceptable, the dynamic version of the Kaleckian baseline model would not get rid of the Keynesian stability condition either.

Even if the Keynesian stability condition is approved, there is still a second problem that often goes unnoticed. It will become more serious when the model is extended and thus gets so complex that its analysis has to rely on numerical simulations. To illustrate the problem, consider the steady-state values that, with reference to the US economy, will later be employed in our own numerical calibration. These are a depreciation rate $\delta=10$ per cent, a profit share $h=31$ per cent, a growth rate $g=2.50$ per cent, and an output-capital ratio $u=0.90$. The corresponding profit rate is $r=17.9$ per cent and from equation (2), $g=s_{r} r$, the saving propensity $s_{r}$ is residually determined as $s_{r}=$ $2.5 / 17.9=0.14$ (rounded). For equation (7) with the predetermined growth rate (or if we assume $\beta=0$ right away), this implies a short-run investment multiplier of

$$
\frac{\partial u}{\partial g} \stackrel{(7)}{=} \frac{1}{s_{r} h}=\frac{1}{0.043}=23 .
$$

If a dynamic model is to generate cycles in the output-capital ratio with an amplitude that realistically is not larger than \pm 3 per cent (!), which is the order of magnitude that we observe for the US between 1983 and 2007 (the period of the 'Great Moderation'), then $u$ would oscillate between 0.873 and $0.92 .^{7}$ Hence equation (9) means that because of this effect the capital growth rate will vary with an amplitude of less than $\pm 0.027 / 23= \pm 0.12$ percentage points, that is, $g$ would oscillate between 2.38 per cent and 2.62 per cent. This range is rather narrow and would be a serious underestimation of the empirical variations.

The disproportionate amplitudes can be more than a cosmetic issue. Growth models with financial ratios, especially - such as a ratio of the corporate debt of firms to their capital stock - would typically give rise to very limited fluctuations in these variables. ${ }^{8}$ This is not only unpleasant but it might even affect their qualitative co-movements with the utilization rate. In models that moreover purport to exhibit a Minskyan flavour, the financial ratios often enter as an argument in the decisions of firms or commercial

6. Utilization $u$ would here coincide with desired utilization $u_{d}$ if (and only if) the trend growth rate $g^{*}$ in (3) satisfied $g^{*}=s_{r}\left(b u_{d}-\delta\right)$ as a consistency condition.

7. The exclamation mark has been added to the \pm 3 per cent amplitude of $u$ because one finds many numerical illustrations in the literature with considerably wider oscillations.

8. Examples from the literature can be found in section 7 of the extended version of this paper, Franke (2015). 
banks. The minor variations of, say, a debt-asset ratio with perhaps counterintuitive leads or lags would then jeopardize the explanatory power of such a model.

Very similar expressions to equations (5) or (9) are obtained for other specifications of aggregate saving that are standard in post-Keynesian modelling. Excessively large values for these multipliers are therefore a universal phenomenon. Surely, they may be passed by if the pedagogical merits of a model are predominant. For more ambitious models, however, the small denominator in the solution for IS utilization and the resulting high sensitivity of utilization to changes in the capital growth rate (and other economic variables as well) becomes a problem that can no longer be neglected.

One way out of this dilemma, if the notion of goods market clearing is to be preserved, could be a reconsideration of the usual saving specifications. The remedy is to reduce the direct effects of total income (and thus total output or the output-capital ratio, respectively). Instead, the level of saving may also be linked to other variables such as interest or dividend payments, if these are predetermined variables in a model. One stimulation in this direction could be the saving function postulated by Hein/Schoder (2011) in their empirical investigation (cf. their equations (10) and (13) on pp. 696f). Another and more involved treatment referring to financial variables and dynamic adjustments can be found in some papers by Skott and Ryoo (for example, Skott 1989: sec. 4.10; Skott/Ryoo 2008: sec. 3.1.3; Ryoo/Skott 2015: sec. 2.2.3).

Our contribution proposes a less radical way and basically sticks to the concepts underlying the above saving function (2). The only direction into which the baseline model is extended is the introduction of government spending and, therefore, taxes as one of its financing sources. Obviously, the multiplier effects could also be weakened by postulating a counter-cyclical fiscal policy, but our results should not depend on this feature. The primary subject will be the modification of the investment multiplier by taxes that in a more or less direct way change with economic activity and so have an adverse effect on aggregate demand.

\section{INTRODUCTION OF A GOVERNMENT SECTOR}

This section adds a government sector to the canonical Kaleckian model. Government expenditures are financed by taxes and, if a gap still persists, by the issuance of new bonds. Four types of taxes are considered: taxes on wages, on rentiers income, on corporate income, and on production. All of them change proportionally with the corresponding tax base. For simplicity, the households are supposed to be taxed identically, with the tax rate $\tau_{p}$ on Personal income. ${ }^{9}$ The tax rate on Corporate income is designated $\tau_{c}$, and $\tau_{v}$ denotes the tax rate on the volume of production, or (gross) Value added.

The profit share $h$ is now based on the gross value added of the firms after subtracting the production tax,

$$
h=\left[\left(1-\tau_{v}\right) p Y-w L\right] /\left(1-\tau_{v}\right) p Y,
$$

where $p$ is the price level, $Y$ total output, $w$ the nominal wage rate, and $L$ the volume of employment. Accordingly, total wages (before the personal income tax) are $w L=\left(1-\tau_{v}\right)(1-h) p Y$, and the wage share is $1-h=w L /\left(1-\tau_{v}\right) p Y$. The profit

9. A differentiation between payroll taxes and taxation of capital income (or within different kinds of capital incomes) would be straightforward. 
rate $r$ (that is, the operating surplus net of depreciation divided by the replacement value of the capital stock $p K)$ is given by $r=\left[\left(1-\tau_{v}\right) p Y-w L-\delta p K\right] / p K$. Hence

$$
r=\left(1-\tau_{v}\right) h u-\delta \text {. }
$$

As a first step for future extensions of the financial relationships in the economy, we also include a rudimentary banking sector. It is purely passive, which means the banks accept deposits from the rentier households and forward them as business loans to the firms; the interest rates on deposits and loans are identical $(j)$; and banking involves neither costs nor profits (neither households nor firms hold cash and the amount of loans is equal to the amount of deposits). $D$ being their stock of debt, firms pay interest $j D$ to the banks and these are directly transferred to the rentiers.

In addition, the rentiers earn dividends on the shares they are holding. In line with the previous saving function (2) it is assumed that the firms retain no earnings. So the rentiers receive from the firms what is left after they paid their interests and the corporate taxes (the base of this tax rate $\tau_{c}$ being $r p K-j D$ ). Lastly, the rentiers own the outstanding government bonds $B$ and receive the interest rate $i$ on them. Normalizing the financial assets by the capital stock for the later analysis, $b=B / p K$ and $d=D / p K$, the income of the rentiers before tax sums up to:

$$
\left(1-\tau_{c}\right)(r-j d) p K+j D+i B=\left\{\left(1-\tau_{c}\right)\left[\left(1-\tau_{v}\right) b u-\delta-j d\right]+j d+i b\right\} p K .
$$

Regarding the demand of the private household sector, the classical saving hypothesis is maintained: the workers consume all of their wages and the rentiers save a constant fraction $s_{r}$ of their income. Taking account of the common personal income tax rate $\tau_{p}$, total consumption expenditures $p C$ of the two groups amount to:

$$
p C=\left(1-\tau_{p}\right)\left\{\left(1-\tau_{v}\right)(1-h) u+\left(1-s_{r}\right)\left\{\left(1-\tau_{c}\right)\left[\left(1-\tau_{v}\right) h u-\delta-j d\right]+j d+i b\right\}\right\} p K .
$$

Government spending $G$ on goods consists of two components. The first one $\left(G^{n}\right)$ constitutes a benchmark and is supposed to grow in step with normal output $Y^{n}$, which in turn is given by a utilization rate $u^{n}$ of the capital stock in place that the government reckons to be normal, $Y^{n}=u^{n} K{ }^{10}$ Let $\gamma_{n}$ be the constant proportionality factor determining $G^{n}$, so that $G^{n}=\gamma_{n} Y^{n}=\gamma_{n} u^{n} K$. The second component of public spending can allow for a straightforward counter-cyclical fiscal policy: the government may seek to revitalize the economy in times of underutilization $Y<Y^{n}$, or dampen it in a boom when $Y>Y^{n}$. The intensity of this counter-cyclical behaviour is measured by a nonnegative coefficient $\gamma_{c}$. Incidentally, a positive $\gamma_{c}$ need not necessarily signify an active policy but may also be explained by lower (higher) contractual government transfers in good (bad) times, so that $\gamma_{c}$ would capture some elements of the 'automatic stabilizers'. In sum, government spending is given by $G=\gamma_{n} Y^{n}-\gamma_{c}\left(Y-Y^{n}\right)$, or

$$
G=\left[\gamma_{n} u^{n}-\gamma_{c}\left(u-u^{n}\right)\right] K \text {. }
$$

The remaining two components of aggregate demand are replacement investment $\delta K$ and net investment $g K$. To ease the discussion, the capital growth rate will from now on be treated as a predetermined variable. That is, the investigation will focus on the size of the multiplier effects from exogenous variations of net investment. Dividing the market

10. To avoid distracting discussions later on, suppose that $u^{n}$ is equal to the desired output-capital ratio of the firms in the previous section. 
clearing condition $Y=C+g K+\delta K+G$ by $K$, invoking (13), (14) and collecting terms, the IS output-capital ratio $u$ is thus determined as:

$$
\begin{aligned}
u & =u(g, b, d)=\frac{g+c_{b} i b+c_{d j} j+c_{o}}{D}, \quad \text { where } \\
D & =D\left(\tau_{p}\right) \\
& =\gamma_{c}+\tau_{v}+\tau_{p}\left(1-\tau_{v}\right)+\left(1-\tau_{v}\right)\left(1-\tau_{p}\right)\left[s_{r}+\tau_{c}\left(1-s_{r}\right)\right] h \\
c_{b} & =c_{b}\left(\tau_{p}\right)=\left(1-s_{r}\right)\left(1-\tau_{p}\right) \\
c_{d} & =c_{d}\left(\tau_{p}\right)=\left(1-s_{r}\right)\left(1-\tau_{p}\right) \tau_{c} \\
c_{o} & =c_{o}\left(\tau_{p}\right)=\left(\gamma_{n}+\gamma_{c}\right) u^{n}+\left[1-\left(1-s_{r}\right)\left(1-\tau_{p}\right)\left(1-\tau_{c}\right)\right] \delta .
\end{aligned}
$$

Emphasizing the dependence of the auxiliary terms upon the tax rate $\tau_{p}$ will be useful for the analysis in the next section.

The ratio $1 / D$ measures the investment multiplier, $\partial u / \partial g=1 / D$. Clearly, in the absence of taxes and an active fiscal policy $\left(\gamma_{c}=\tau_{v}=\tau_{c}=\tau_{p}=0\right), 1 / D$ reduces to the familiar $1 / s_{r} h$ in equation (9). For the general case it is readily checked that each of the tax rates has a positive effect on $D$ and can therefore reduce the multiplier. The economic argument is straightforward: higher taxes weaken the impact of output variations on consumption, without directly affecting the other components of aggregate demand. The less trivial issue is whether the resulting decrease in $1 / D$ would also be quantitatively significant; this question will have to be examined below. In addition it may be observed that a reduction of $1 / D$ could likewise be brought about by a pronounced counter-cyclical spending rule, $\gamma_{c}>0$, although our analysis will not dwell on this option.

Besides the capital growth rate $g$, equation (15) makes the dependence of economic activity upon the two debt-to-capital ratios $b$ and $d$ explicit. It may not go unnoticed that as long as the two ratios do not instantaneously feed back on $g$ via an extended investment function, IS utilization is increasing in both of them. Of course, this is due to the interest income effects in the consumption demand (13) (whereas possible negative effects of higher indebtedness may only work out over time). Similarly, utilization rises with either of the two interest rates $i$ and $j$.

\section{THE STEADY-STATE POSITION}

The output-capital ratio in (15) cannot be readily interpreted as a long-run equilibrium solution. For that, it has to be taken into account that the two debt ratios $b$ and $d$ follow an intrinsic dynamics, so that $u=u(g, b, d)$ will not remain constant either. The ratios are generally varying in the course of time because the firms have to borrow $\dot{D}$ to finance investment, and the government has to issue new bonds $\dot{B}$ to finance its deficit. This feature prompts us to identify the rest points of $b$ and $d$, even though as yet no complete fully fledged model has been set up. For the framework to be meaningful, it should moreover be checked whether the conditional adjustment processes are stable for each of the variables (that is, conditional on the assumption that the other variables stay put).

Let us begin with the debt dynamics of the firm sector. In addition to the assumption that the firms pay out all of their profits to the shareholders, we follow much of the literature and 
(explicitly) assume a constant number of equities. ${ }^{11}$ Net investment is thus exclusively financed by raising new credits, $g p K=\dot{D}$. As $\dot{d}=d(D / p K) / d t=\dot{D} / p K-(\pi+g) d$ (where $\pi$ : $=p=\dot{p} / p$ is the constant rate of price inflation), we have the simple relationship

$$
\dot{d}=g-(g+\pi) d .
$$

As long as the growth rate $g+\pi$ of the nominal output is positive, these adjustments are stable. Working with an exogenously given equilibrium level $g=g^{o}$ of the capital growth rate, process (16) is independent of the rest of the economy and the debt-asset ratio converges to

$$
d^{o}=g^{o} /\left(g^{o}+\pi\right) .
$$

(Here and in the following, a superscript ' $o$ ' may indicate steady-state values.) Turning to the model's implication for the government bonds, we first sum up the (nominal) tax revenues $T$, normalized by the capital stock:

$$
\begin{aligned}
T / p K= & \tau_{v} u+\tau_{p}\left(1-\tau_{v}\right)(1-h) u+\tau_{p}\left(1-\tau_{c}\right)\left[\left(1-\tau_{v}\right) h u-\delta-j d\right]+\tau_{p} j d \\
& +\tau_{p} i b+\tau_{c}\left[\left(1-\tau_{v}\right) h u-\delta-j d\right] \\
= & \left\{\tau_{v}+\left(1-\tau_{v}\right)\left[\tau_{p}+\tau_{c}\left(1-\tau_{p}\right) b\right]\right\} u+\tau_{p} i b-\tau_{c}\left(1-\tau_{p}\right) j d-\left[\tau_{c}+\tau_{p}\left(1-\tau_{c}\right)\right] \delta .
\end{aligned}
$$

The first term after the first equals sign represents the taxes on the gross value added, the second the taxes on wages, the third the taxes on the dividend payments, the fourth and fifth the taxes on the rentiers' interest income from their deposits and government bonds, respectively, and lastly the sixth term captures the taxes on corporate income.

The financing of the government deficit by new bonds gives rise to a second dynamic equation, $\dot{B}=p G+i B-T$. From $\dot{b}=d(B / p K) / d t=\dot{B} / p K-(\pi+g) b$ together with equations (14) and (18), the following differential equation for the bond ratio is obtained:

$$
\begin{aligned}
\dot{b}= & {\left[\left(1-\tau_{p}\right) i-g-\pi\right] b+\tau_{c}\left(1-\tau_{p}\right) j d+\left[\tau_{c}+\tau_{p}\left(1-\tau_{c}\right)\right] \delta+} \\
& \left(\gamma_{n}+\gamma_{c}\right) u^{n}-\left\{\gamma_{c}+\tau_{v}+\left(1-\tau_{v}\right)\left[\tau_{p}+\tau_{c}\left(1-\tau_{p}\right) b\right]\right\} u(g, b, d) .
\end{aligned}
$$

Because government bonds are relatively safe, the after-tax bond rate $\left(1-\tau_{p}\right) i$ should not exceed the nominal growth rate $g+\pi$. Since, furthermore, utilization $u=u(g, b, d)$ is increasing in $b$, we can be, rather, sure of a negative derivative $\partial \dot{b} / \partial b<0$. That is, the bond dynamics when taken on its own is a stable adjustment process, too.

Going back to equation (18) for the tax collections and neglecting a possible countercyclical fiscal policy $\left(\gamma_{c}=0\right)$, the ratio of the primary deficit to GDP in a state where $\dot{b}=0$ is readily seen to be given by

11. This assumption remains often implicit in the literature. It implies that stock prices must rise at least if in a steady-state position the rentiers are required to allocate their wealth in fixed proportions between equities, deposits and government bonds. For simplicity, the resulting capital gains are not supposed to feed back on the real sector. Given that over most of the past 3 decades US firms issued no new shares but rather bought them back from the market, a constant number of equities appears an acceptable benchmark. For a more general framework it would have to be recognized that the debt-to-capital ratio, the equity-to-capital ratio and Tobin's $q$ are not independent of one another, so that further assumptions or specifications would have to be introduced; see Franke/ Yanovski (2016) for a more explicit treatment of these relationships in an otherwise elementary framework. 


$$
\frac{p G}{p Y}-\frac{T}{p Y}=\gamma_{n} \frac{u^{n}}{u}-\frac{T}{p Y}=\left(g^{o}+\pi-i\right) b / u .
$$

As the difference between $g^{o}+\pi$ and the (pre-tax) bond rate will be rather small, the (full) government deficit will essentially amount to the interest payments, that is, we have deficit $p Y=(p G+i B-T) / p Y \approx i B / p Y$. With familiar figures (in former times) like $i=5$ per cent and $B / p Y=60$ per cent, we also get a familiar deficit ratio of 3 per cent.

The present set-up can already be used to analyse certain elementary issues of a socalled 'functional finance', the theory of which goes back to Lerner (1943) and still remains influential in the contemporary post-Keynesian work on fiscal policy and public debt. Therefore, before turning to a numerical calibration of the model components, we devote the rest of this section to a policy problem that was recently addressed by Ryoo/ Skott $(2013$; 2015) within a similar modelling framework, when they were concerned with the necessary long-run requirements for a full-employment growth path. In this context one asks for suitable combinations of the government consumption coefficient $\gamma_{n}$, the tax rates $\tau_{v}, \tau_{c}, \tau_{p}$, and the equilibrium debt ratio $b^{o}$ that can bring about a given natural growth rate $g^{o}$ and a given level $u^{n}$ of normal utilization. ${ }^{12}$ Ryoo/Skott (2013: 518f; 2015: sec. 2.3) obtain what at first sight appear to be two striking implications of their analysis. First, a reduction of government consumption necessarily increases (rather than decreases) the long-run debt ratio. Second, a higher natural growth rate lowers the required debt ratio. ${ }^{13}$ For a more detailed assessment of these statements it has, however, to be added that these changes go along with adjustments in the tax rate on personal income. In particular, the first result is less astonishing if it is realized that the lower spending ratio $\gamma_{n}$ allows the government to reduce taxes.

Treating their coefficient of government consumption as given, Ryoo and Skott compute the steady-state values of the debt ratio $b^{o}$ and their income tax rate $\tau$ (which is their only tax rate) in a two-step procedure. First, they can solve the model for $b^{o}$, where interestingly this value turns out to be independent of $\tau$. The tax rate compatible with $g^{o}$ and $u=u^{n}$ is calculated subsequently and has $b^{o}$ as one of its determinants. Things are not so straightforward in the present model. If we fix the government spending ratio $\gamma_{n}$ and the two tax rates $\tau_{v}$ and $\tau_{c}$, the equilibrium values of the debt ratio $b$ and the remaining tax rate $\tau_{p}$ on personal income are mutually interdependent.

We tackle this problem by devising two steady-state relationships where $b$ can be formally written as a function of $\tau_{p}$. One of them turns out to be increasing, the other decreasing, and their point of intersection yields the unique long-run equilibrium pair $\left(b^{o}, \tau_{p}\right)$. The first function is obtained by reversing the causality in the IS equation. We thus focus on the values of $b$ that support normal utilization under variations of $\tau_{p}$. Accordingly, we fix $u=u^{n}$ on the left-hand side of (15) together with $d=d^{o}$ on the right-hand side and, making use of the terms $D=D\left(\tau_{p}\right)$, etc., solve this equation for $b$. Referring to these values as $b=b_{I S}^{o}\left(\tau_{p}\right)$, our first function reads:

$$
b_{I S}^{o}\left(\tau_{p}\right)=\frac{D\left(\tau_{p}\right) u^{n}-g^{o}-c_{d}\left(\tau_{p}\right) j d^{o}-c_{o}\left(\tau_{p}\right)}{c_{b}\left(\tau_{p}\right) i} .
$$

12. The natural growth rate is then, of course, determined by the growth of productivity and the labour force. In addition to $\dot{b}=0$ and $u^{o}=u^{n}$, full employment in a steady state will prevail if another condition on the ratio of the capital stock to the labour force is fulfilled (Ryoo/Skott 2015: 11).

13. As noted by Ryoo/Skott (2015: 11, fn 11), similar results have also previously been obtained in other settings. 
The second relationship derives from the government debt dynamics. It is concerned with the values of $b$ and $\tau_{p}$ that bring about $\dot{b}=0$ in (19), where $u=u\left(g^{o}, b^{o}, d^{o}\right)=u^{n}$ is already presupposed to prevail, besides $d=d^{0}$. The solution of this equation for the debt ratio provides us with a second function $b=b_{G D}^{o}\left(\tau_{p}\right)$ (the index 'GD' may stand for government debt),

$$
\begin{aligned}
b_{G D}^{o}\left(\tau_{p}\right) & =\frac{a_{1}\left(\tau_{p}\right)-a_{2}\left(\tau_{p}\right) u^{n}+\gamma_{n} u^{n}}{a_{3}\left(\tau_{p}\right)} \\
a_{1} & =a_{1}\left(\tau_{p}\right)=\tau_{c}\left(1-\tau_{p}\right) j d^{o}+\left[\tau_{c}+\tau_{p}\left(1-\tau_{c}\right)\right] \delta \\
a_{2} & =a_{2}\left(\tau_{p}\right)=\tau_{v}+\left(1-\tau_{v}\right)\left[\tau_{p}+\tau_{c}\left(1-\tau_{p}\right) h\right] \\
a_{3} & =a_{3}\left(\tau_{p}\right)=g^{o}+\pi-\left(1-\tau_{p}\right) i .
\end{aligned}
$$

It is spelled out in Appendix 1 that the numerator of (21) is increasing in $\tau_{p}$, while the denominator is obviously decreasing. Hence $b_{I S}^{o}$ is an increasing function of the tax rate $\tau_{p}$. For $b_{G D}^{o}$ the opposite applies: its numerator is decreasing and its denominator increasing in $\tau_{p}$, so that $b_{G D}^{o}$ decreases with rising values of $\tau_{p}$.

It is furthermore easily seen that the numerator of $b_{I S}^{o}$ (of $b_{G D}^{o}$ ) depends negatively (positively) on the government consumption ratio $\gamma_{n}$, and the denominators of (21) and (22) are both independent of it. Referring to the $\left(\tau_{p}, b\right)$ plane with the tax rate on the horizontal axis, we can thus say that an increase in $\gamma_{n}$ shifts the curve $b_{I S}^{o}$ downward and the curve $b_{G D}^{o}$ upward (or to the right). As illustrated in Figure 1, the new point of intersection of the two curves will therefore lead to a higher tax rate $\tau_{p}$, whereas we get an ambiguous conclusion for the equilibrium debt ratio $b^{o}$ : whether it increases or decreases depends on how far the curves will shift relative to one another. Figure 1 depicts a situation with a moderately lower debt ratio. This is in fact the outcome that we obtain from the numerical values that will be introduced in the next section. Note that this reaction corresponds to the result by Ryoo/Skott $(2013 ; 2015)$ mentioned above. ${ }^{14}$



Figure 1 The curves $\mathrm{b}_{\mathrm{IS}}^{\mathrm{o}}$ and $\mathrm{b}_{\mathrm{GD}}^{\mathrm{o}}$ and their reactions to an increase in $\gamma_{\mathrm{n}}$

14. It may be added in passing that numerically, over a relevant range, both function $b_{I S}^{o}$ and $b_{G D}^{o}$ are practically linear in $\tau_{p}$ (although $\tau_{p}$ enters both the numerator and the denominator of these ratios). 
Table 1 Signs of the partial derivatives of $\mathrm{b}_{\mathrm{IS}}^{\mathrm{o}}$ and $\mathrm{b}_{\mathrm{GD}}^{\mathrm{o}}$

\begin{tabular}{llllll}
\hline \multicolumn{2}{l}{ Derivatives with respect to } & & & \\
& $\tau_{p}$ & $\gamma_{n}$ & $g^{o}$ & $s_{r}$ & $b$ \\
\hline$b_{I S}^{o}$ & + & - & - & + & + \\
$b_{G D}^{o}$ & - & + & - & 0 & - \\
\hline
\end{tabular}

Note: ' + ' and ' - ' indicate a positive and negative partial derivative, respectively.

The analysis of the steady-state effects of ceteris paribus changes in the equilibrium growth rate $g^{o}$, the saving propensity $s_{r}$ and the profit share $h$ can be carried out in the same manner. The signs of the partial derivatives of $b_{I S}^{o}$ and $b_{G D}^{o}$ are given in Table 1. It follows that an exogenous rise in $g^{o}$ shifts both curves downward. This definitely lowers the debt ratio $b^{o}$, but at the current qualitative line of reasoning the tax rate may change either way. If the rentiers' saving propensity increases without affecting the growth rate, the $b_{I S}^{o}$ curve shifts upward while the $b_{G D}^{o}$ stays put. Hence the debt ratio rises in this case and the tax rate will be lowered. If we consider an exogenous fall in the profit share, we have the same argument as for the increase in $\gamma_{n}$. Conversely, a higher profit share would allow the government to reduce the taxes on personal income (with a numerical calibration, it may be interesting to check the net effect on workers' income).

These steady-state comparisons should nevertheless be taken with care. Given that, realistically, tax rates are not easily adjusted, the discussion may rather suggest that at least for a longer period of time the economy will not be able to reach such a state of long-run consistency. A more careful investigation of this problem is, however, beyond the present limited framework and would require a more elaborated dynamic model, which is a challenge for future research.

\section{CALIBRATION}

Assessing the multiplier effects $\partial u / \partial g=1 / D$ for the IS solution (15) requires a numerical analysis. To this end concrete numerical values have to be assigned to the parameters in our model and to some of the variables, which will be supposed to prevail in a steady-state position (the latter values may be referred to as 'parameters' as well). This is a relatively unproblematic task for the parameters collected in Table 2. They are based on quarterly US data for the non-financial corporate business sector over the period 1983Q1-2007Q2, which is the time of the so-called Great Moderation until just the first indications of the financial crisis. The data sources are given in Appendix 1.

For most of the parameters we compute the time averages over the sample period and round them a little. Slight exceptions are the depreciation rate $\delta$ and the degree of government indebtedness $B / p Y$. Regarding $\delta$, we have distinct figures from two data sets and choose a value somewhere in the middle. Regarding $B / p Y$, figures differ according to the underlying statistical concepts. Here we just choose a familiar order of magnitude for the time before the crisis. ${ }^{15}$ In addition, we set $\gamma_{c}=0$ since our multiplier effects should not depend on special assumptions on a counter-cyclical fiscal policy.

It may be mentioned as an aside that according to its definition in (11), the values for $u, h$ and $\delta$ imply a profit rate of $r=15.53$ per cent. The interest burden of the

15. See, for example, http://en.wikipedia.org/wiki/National_debt_of_the_United_States (July 2015). 
Table 2 Empirical time averages (1983Q1-2007Q2) and parameters set in the model

\begin{tabular}{lccccc}
\hline & $u$ & $h$ & $\delta$ & $g$ & $\pi$ \\
\hline Emp. averages & 0.915 & 31.04 & - & 2.38 & 2.43 \\
Model settings & 0.900 & 31.00 & 10.00 & 2.50 & 2.50 \\
\hline & $i$ & $j$ & $B / p Y$ & $\tau_{v}$ & $\tau_{c}$ \\
\hline Emp. averages & 5.08 & 7.91 & - & 8.52 & 28.14 \\
Model settings & 5.00 & 8.00 & 60.00 & 8.50 & 28.00 \\
\hline
\end{tabular}

Note: All figures except $u=Y / K$ in per cent. Data sources in Appendix 1.

government amounts to $i B / p Y=0.05 \cdot 0.60=3$ per cent of the economy's total income. Since the nominal growth rate $g^{o}+\pi$ happens to equal the bond rate $i$, equation (20) tells us that the government has a balanced primary budget, $p G=T$. In other words, its deficit is just made up of its interest payments. A deficit of 3 per cent is also quite close to the empirical time average.

The government's debt-to-capital ratio in the equilibrium is $b=b^{o}=B / p K=(B / p Y)(p Y / p K)=0.60 \cdot 0.90=0.54$. Regarding the private sector, the debt-asset ratio of the firms in a steady state is $d=d^{o}=g^{o} /\left(g^{o}+\pi\right)=0.50$; see equation (17). ${ }^{16}$

Three parameters thus remain to be determined: the rentiers' saving propensity $s_{r}$, the government's normal spending ratio $\gamma_{n}=G^{n} / Y^{n}$, and the tax rate $\tau_{p}$ on personal income. The latter two parameters are interrelated if the government is to keep its deficit within bounds. Supposing that normal utilization $u=u^{n}$ prevails in a long-run equilibrium, $\gamma_{n}$ is obtained as a linear function of $\tau_{p}$ by setting $\dot{b}=0$ and $u(g, b, d)=u^{n}$ in equation (19). Subsequently the saving propensity $s_{r}$, which does not show up in (19), can be determined from the goods market equilibrium. That is, the expression $u\left(g^{o}, b^{o}, d^{o}\right)$ in (15) is set equal to $u^{n}=0.90$ and, with $\tau_{p}$ and $\gamma_{n}$ given, the equation is solved for $s_{r}$. Schematically,

$$
\gamma_{n} \stackrel{(19)}{=} \gamma_{n}\left(\tau_{p}\right) \quad \text { and } \quad s_{r} \stackrel{(15)}{=} s_{r}\left(\tau_{p}, \gamma_{n}\right)
$$

On this basis, we vary the tax rate $\tau_{p}$, compute the corresponding values of $\gamma_{n}$ and $s_{r}$, and check the implications of these numerical scenarios. In the first instance we are, of course, interested in the resulting investment multiplier $\partial u / \partial g=1 / D ; D$ as determined in (15). A numerical target value that we would like the model to achieve is readily derived as follows. From the data described in the appendix we take the quarterly time series of the (annualized) capital growth rate $g_{t}$ and the output-capital ratio $u_{t}$ and detrend them by the Hodrick-Prescott filter. ${ }^{17}$ Computing for these trend deviations $\hat{g}_{t}, \hat{u}_{t}$ the standard deviations $\sigma\left(\hat{g}_{t}\right)$ and $\sigma\left(\hat{u}_{t}\right)$ over the abovementioned sample period, we employ the ratio $\sigma\left(\hat{u}_{t}\right) / \sigma\left(\hat{g}_{t}\right)$ as our benchmark for the multiplier $\partial u / \partial g$. This is the value given in the right-hand column of Table 3. The fact that this statistic turns out to be more than ten times lower than the value in (9) for the taxless economy is already sufficient evidence that the simple modelling framework does have a problem when it comes to elementary numerical inspections.

16. Obviously, the ratio would be lower if the firms retained some of their earnings.

17. The conventional smoothing parameter is $\lambda=1600$ for quarterly data. This is actually not fully appropriate in the present case because the HP-trend of $u_{t}$ still exhibits some variability at a business cycle frequency. A stronger smoothing is necessary to let it disappear. We actually decided on $\lambda=51,200$, which is $2^{5}$ times higher than the standard value. 
Table 3 Empirical time averages (1983Q1-2007Q2) and model benchmark values

\begin{tabular}{lll}
\hline & $T / p Y$ & $\partial u / \partial g$ \\
\hline Emp. averages & 28.60 & 2.20 \\
Benchmark values & 28.50 & 2.20 \\
\hline
\end{tabular}

Reasonable multiplier effects should not be the only concern in our effort to calibrate the model. At the same time the tax payments - or what amounts to the same: the government spending - should not get out of range. We thus take the tax-to-income ratio $T / p Y$ in Table 3 as a second benchmark. For the model we can invoke equation (18) and compute it as $T / p Y=(T / p K) \cdot u^{n}$.

Because of its analogy to the estimation approach known as the method of simulated moments (Lee/Ingram 1991; Franke 2009), which will immediately become apparent, the two statistics $\partial u / \partial g$ and $T / p Y$ may also be referred to as 'moments'. The first, for short, is our multiplier moment and the second our tax moment, where the desired values may be denoted as $(\partial u / \partial g)^{d}$ and $(T / p Y)^{d}$, respectively. If at all, we cannot expect that variations of a single parameter like $\tau_{p}$ will be able to match both of them. Generally, we are in search of a value of $\tau_{p}$ such that the thus generated moments come as close as possible to the desired moments. To quantify this 'as close as possible', we introduce a weighting coefficient $\omega(0 \leq \omega \leq 1)$ and set up an objective function $L$ (for 'loss function') that expresses the quality of the match in percentage terms:

$$
\begin{aligned}
L_{\omega} & =\omega\left|\operatorname{Dev}_{M}\right|+(1-\omega)\left|\operatorname{Dev}_{T}\right| \\
& :=\omega\left|\frac{100 \cdot\left[\partial u / \partial g-(\partial u / \partial g)^{d}\right]}{(\partial u / \partial g)^{d}}\right|+(1-\omega)\left|\frac{100 \cdot\left[T / p Y-(T / p Y)^{d}\right]}{(T / p Y)^{d}}\right| .
\end{aligned}
$$

For completeness we can reassure readers that according to the procedure sketched above and with respect to a given value of $\omega$, the loss is ultimately a function of the personal income tax rate $\tau_{p}$ alone.

The coefficient $\omega$ represents the priority that the multiplier moment is given relative to the tax moment. In the polar case $\omega=1$, we do not care about a possible mismatch of the latter, while in the case of $\omega=0$ it is the multiplier moment that is completely ignored. Given $\omega$, we are looking for a tax rate $\tau_{p}$ that minimizes the loss $L_{\omega}=L_{\omega}\left(\tau_{p}\right)$. In percentage terms, it gives us the smallest possible average deviation of the model generated from the desired moments.

To begin with, let us consider an equal weight on the two moments, $\omega=0.50$. It was already observed in Section 3 that an increase (decrease) in the tax rates reduces (raises) the multiplier $\partial u / \partial g$. So with high enough values for $\tau_{p}$ we should be able to bring the multiplier down to the desired level $(\partial u / \partial g)^{d}$. The tax ratio $T / p Y$, on the other hand, can be raised (lowered) by increasing (decreasing) $\tau_{p}$. Combining these effects in the loss function $L_{\omega}=L_{\omega}\left(\tau_{p}\right)$, a value of $\tau_{p}$ can be expected to exist that minimizes the weighted deviations of the two moments from their benchmarks. The question remaining is whether such a minimum is attained at a tax rate that is not too extreme.

The properties of the function are illustrated in Figure 2. It is well behaved and exhibits a unique minimum slightly higher than 20 per cent. The exact value is $\tau_{p}=20.57$ per cent (rounded). This rate brings about an average moment deviation of $L_{\omega}=5.83$ per cent, though the single matches are rather distinct. The tax moment is actually perfectly matched, $\operatorname{Dev}_{T}=0$, whereas the multiplier moment deviates by 


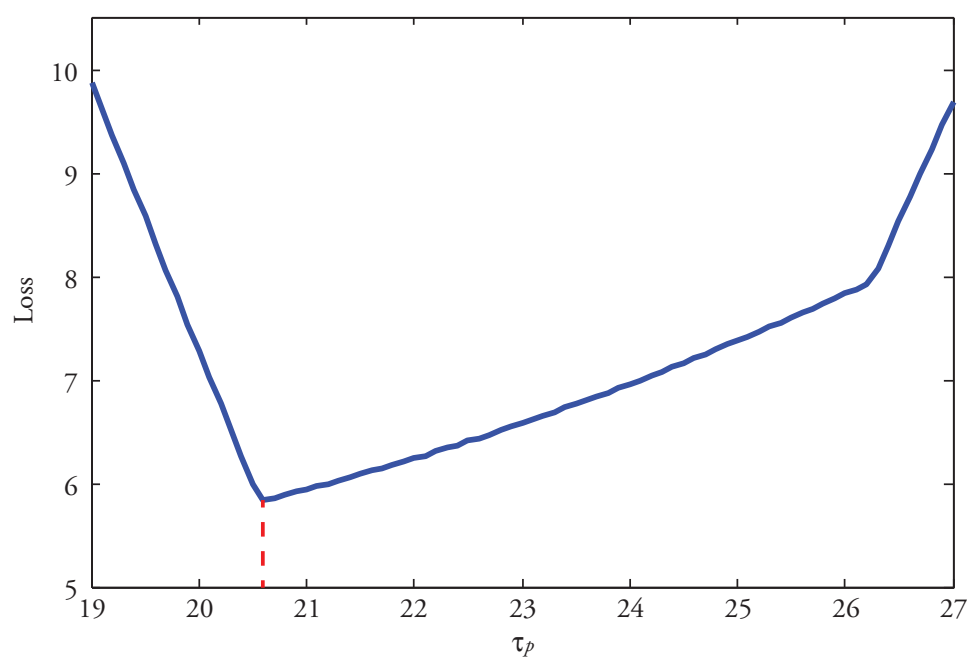

Figure 2 The function $\tau_{\mathrm{p}} \mapsto \mathrm{L}_{\omega}\left(\tau_{\mathrm{p}}\right)$, given $\omega=0.50$

Table 4 Optimal $\tau_{\mathrm{p}}$ under variations of weight $\omega$ in $\mathrm{L}_{\omega}$ (values in per cent)

\begin{tabular}{|c|c|c|c|c|c|}
\hline \multirow{2}{*}{$\frac{\text { Weight } \omega}{\text { Optimal } \tau_{p}}$} & \multirow{2}{*}{$\begin{array}{c}0.54 \\
20.57\end{array}$} & \multirow{2}{*}{$\frac{0.57297}{22.91}$} & \multicolumn{2}{|c|}{0.60} & 0.61 \\
\hline & & & 25.32 & 26.24 & 26.25 \\
\hline $\begin{array}{l}L_{\omega} \\
\operatorname{Dev}_{M} \\
\operatorname{Dev}_{T}\end{array}$ & $\begin{array}{r}6.30 \\
11.66 \\
0.00\end{array}$ & $\begin{array}{l}6.55 \\
6.55 \\
6.55\end{array}$ & $\begin{array}{r}6.36 \\
1.74 \\
13.31\end{array}$ & $\begin{array}{r}6.36 \\
0.02 \\
15.88\end{array}$ & $\begin{array}{r}6.20 \\
0.00 \\
15.91\end{array}$ \\
\hline $\begin{array}{l}s_{r} \\
s_{h}\end{array}$ & $\begin{array}{r}43.64 \\
9.11\end{array}$ & $\begin{array}{r}44.96 \\
9.39\end{array}$ & $\begin{array}{r}46.42 \\
9.69\end{array}$ & $\begin{array}{r}47.00 \\
9.82\end{array}$ & $\begin{array}{r}47.00 \\
9.82\end{array}$ \\
\hline
\end{tabular}

$L_{\omega} / \omega=5.83 / \omega=11.66$ per cent from the desired multiplier, that is, $\partial u / \partial g=2.46$ versus the desired value of 2.20. Given the order of magnitude for the investment multiplier in the taxless economy, this is certainly remarkable progress.

Obviously, the same result is obtained if greater importance is attached to the tax moment, that is, if lower weights $\omega$ are underlying. Actually, all weights $\omega$ between 0.00 and 0.54 yield the same solution to the minimization problem, the components of which are shown in the second column of Table 4. Increasing $\omega$ above 0.54 raises the tax ratio $T / p Y$ and lowers the multiplier $\partial u / \partial u$, changes which are brought about by higher tax rates $\tau_{p}$. Eventually, at $\omega=0.57297$ and achieved by a tax rate $\tau_{p}=22.91$ per cent, the two deviations $\operatorname{Dev}_{T}$ and $\operatorname{Dev}_{M}$ happen to be equal (third column in Table 4).

A further increase in $\omega$ leads to a further increase in the loss-minimizing tax rate and results in higher tax ratios $T / p Y$, while the multiplier moment continues to improve. Interestingly, at weights around $\omega=0.60$ there is a whole interval of $\tau_{p}$ with practically the same minimal value of the loss function; still existing differences in $L_{\omega}\left(\tau_{p}\right)$ would be of only academic interest (columns 4 and 5 in Table 4). A perfect match for the multiplier moment is achieved at $\omega=0.61$ (last column of in Table 4). The tax ratio, on the other hand, is then $15.91 \%$ higher than desired, $T / p Y=33.03$ per cent versus 
$(T / p Y)^{d}=28.50$ per cent. Clearly, this solution to the minimization problem remains in force for all higher weights, $0.61 \leq \omega \leq 1.00$.

The second-last row in Table 4 reports the rentiers' saving propensity $s_{r}$ associated with the optimal solutions. It is consistently more than three times higher than the value of 14 per cent in the taxless scenario underlying the multiplier in equation (9). Besides being sociologically more plausible, the higher propensity also nicely fits in with a result obtained by Onaran/Galanis (2012: 12), who find that the difference between the propensities to save out of profits and wages is 42.6 per cent for the US (where the latter is zero in the present framework). ${ }^{18}$

Another check can be made by referring to the aggregate saving propensity $s_{h}$ for all private households, rentiers and the non-saving workers together. With disposable income $Y^{d}$ and obvious indices $r$ and $w$ for the two groups,

$$
\begin{aligned}
Y_{r}^{d} & =\left(1-\tau_{p}\right)\left\{\left(1-\tau_{c}\right)\left[\left(1-\tau_{v}\right) h u^{n}-\delta-j d^{o}\right]+j d^{o}+i b^{o}\right\} p K \\
Y_{w}^{d} & =\left(1-\tau_{p}\right)\left(1-\tau_{v}\right)(1-h) u^{n} p K .
\end{aligned}
$$

$s_{h}$ is given by

$$
s_{h}=s_{r} Y_{r}^{d} /\left(Y_{r}^{d}+Y_{w}^{d}\right) .
$$

The last row in Table 4 demonstrates that this propensity is between 9 and 10 per cent. While historically in the US the personal saving rate was lower over the last few decades, it may be brought into consideration that these times were not very close to a balanced growth path and there was often quite some concern about the insufficient savings of households. It is remarkable in this respect that the rate showed a declining trend from 12.5 per cent in the early 1980 s down to 2.5 per cent around 2005 , and that between 1960 and 1980 it fell below the 10 per cent mark for only short intermediate periods. ${ }^{19}$ The 9 to 10 per cent range for our $s_{b}$ should therefore be well acceptable.

Back to the taxes, another feature of the plausibility of the model and its results are the shares of the single tax categories in the total tax revenues. For a rough-and-ready check let us consider the taxes on corporate income, $T_{c}$, versus the sum of payroll and individual income taxes, designated $T_{p}$. The latter are, of course, the dominating category. In number, regarding the federal tax receipts, $T_{p}$ comprised 88 per cent of $\left(T_{p}+T_{c}\right)$ in the year 2014. ${ }^{20}$ In the model, we obtain $T_{p} /\left(T_{p}+T_{c}\right)=82.1$ per cent for the first tax rate $\tau_{p}=20.57$ per cent in Table 4. Clearly, the proportion will rise if the optimal $\tau_{p}$ rises with the weight in the loss function. For $\tau_{p}=26.25$ per cent in the last column of Table 4, the proportion reaches $T_{p} /\left(T_{p}+T_{c}\right)=85.4$ per cent. We can thus say that, also in the composition of the main taxes, the model exhibits no dramatic deviations from the empirical data. ${ }^{21}$

18. I owe this observation to an anonymous referee.

19. See the website of the Federal Reserve Bank of St. Louis (Economic Research) about the personal saving rate, https://research.stlouisfed.org/fred2/series/PSAVERT (July 2015).

20. See http:/en.wikipedia.org/wiki/Taxation_in_the_United_States (Levels and types of taxation; July 2015). For our model, $T_{c}$ is captured by the last term in the first part of equation (18), and $T_{p}$ by the terms $2-5$.

21. If one attaches greater importance to this criterion, one could introduce $T_{p} /\left(T_{p}+T_{c}\right)$ and a desired value of it as a third moment in the loss function, furnished with a weight reflecting the researcher's priority. 


\section{A SHORT NOTE ON SUPPLEMENTING THE NUMERICAL ANALYSIS}

Although the results make good economic sense so far, there is always the question of something better. While it cannot be expected that the variations of one parameter, the personal income tax rate $\tau_{p}$ in the previous section, would be able to bring about a perfect match of two moments, one may wonder whether this would be possible if an additional coefficient were treated as a free parameter. In an extended version of the present paper, this was investigated (Franke 2015: sec. 6). Concentrating on the effects of the corporate tax rate $\tau_{c}$ in this respect, let us briefly summarize the main results there obtained.

- A perfect match of both the tax and the multiplier moment is not possible.

- While better matches are possible by increasing the corporate tax rate $\tau_{c}$, the improvement is rather limited.

- Which pair $\left(\tau_{c}, \tau_{p}\right)$ a researcher may choose in his or her practical work can therefore mainly depend on his or her personal preferences regarding the two moments or the values of the tax rates $\tau_{c}$ and $\tau_{p}$ directly.

While with respect to our two moments the parameter combinations considered above may appear largely satisfactory, they may turn out to be less suitable when the present model components are integrated into a wider framework and one is interested in additional dynamic properties. The idea of moment matching can, however, be readily extended to such more ambitious models; simply include the relevant summary statistics as additional moments in the loss function, specify a number of free parameters, and solve the corresponding loss minimization problem. Franke et al. (2015) and Jang/Sacht (2016) are two examples that show that this approach can be successfully used to estimate (not only asset pricing models but also) fully fledged dynamic macro models in general.

When discussing the strong multiplier effects arising in equations (5) or (9) for the taxless economy in Section 2, reference was also made to possible difficulties in cyclical economies. In particular, it was mentioned that the amplitudes of the debt-to-capital ratios in models of this type may be unrealistically low in relation to the oscillations in utilization. ${ }^{22}$

To get an impression of the cyclical features that the present model with its moderate multiplier effects gives rise to, Franke (2015: sec. 7) conducted a stylized experiment by treating the capital growth rate as an exogenous dynamic variable and positing a deterministic sine wave with a period of 8.50 years and an (empirically supported) amplitude of $g=2.50$ per cent \pm 1.17 per cent for it. The changes in the output-capital ratio $u=$ $u(g, b, d)$ are then determined from the IS solution (15) and the variations in the two debt ratios, which in turn are described by the differential equations (16) and (19). With the numerical calibration from above, this little dynamic system is simulated for so long it develops into a regular and strictly periodical motion. Regarding the resulting co-movements of the variables and their amplitudes we may here report the main properties:

- The firms' debt-asset ratio $d$ lags behind utilization by approximately a quarter of a cycle, with an amplitude of $d=50.00$ per cent \pm 0.79 per cent. Franke (2015: 25) quotes models that typically obtain an even smaller amplitude, and also the lagging behaviour of $d$ (which is important for Minskyan arguments) is not always guaranteed.

22. The relevance of this problem was indicated in Franke (2015: sec. 7) by discussing several examples of elaborated, mostly recent contributions in the literature that are ambitious enough to include a detailed numerical analysis. 
- By contrast, the debt-to-capital ratio of the government $b$ leads utilization by approximately the same time interval. Its variability is nearly three times as high as that of $d$.

- The motions of the ratio of the government deficit to total income, $(p G+i B-T) / p Y$, are practically a negative image of the (pro-cyclical) capital growth rate in that they are counter-cyclical and have a very similar amplitude.

- Interestingly, the tax ratio $T / p Y$ in the deficit term is almost constant; its oscillations are very narrow and lead utilization by less than half a year.

The cyclical features that have been obtained in these experiments are certainly not definitive for future work. They may, however, be seen as a benchmark for fully fledged dynamic models of a financial-real interaction. It is just the highly stylized treatment of cyclical issues that could help them to put their cyclical properties into a better perspective.

\section{CONCLUSION}

The assumption of the clearing of the goods market by instantaneous quantity adjustments and the associated Keynesian stability condition are a dominant practice in heterodox macro modelling. While it is widely known that their theoretical convenience comes at the price of excessively large multiplier effects, there is usually little sincere concern about this problem. It may in fact be neglected as long as one is only interested in the sign of the multipliers, but severe distortions with possibly misleading implications will arise in quantitative work. Although more complex models with, in particular, more detailed dynamic feedbacks might be able to avoid the problem, they are no longer easily related to the results from the ordinary models, so to speak, quite apart from the fact that here no canonical framework has been developed so far.

Referring to the Kaleckian baseline model, the present contribution has advanced a straightforward proposal to cope with the problem. The idea is to include a government sector that, in order to finance its expenditures, levies taxes. It is already intuitively clear that proportional taxes, which are thus directly or indirectly linked to total income, will dampen the original multiplier effects. In addition to pointing out this qualitative feature, the paper turned to numerical issues and demonstrated in a calibration attempt that these effects can also empirically be of a satisfactory order of magnitude.

A specific Kaleckian model had to be used for concreteness. It is nevertheless obvious that in alternative specifications (with a somewhat different but still elementary saving hypothesis, for example) the tax payments could be treated completely analogously and would not essentially affect the feedback mechanisms of the elementary, taxless model. Only the precise formal expression representing the multiplier would be lengthier. We may therefore summarize that the introduction of the proportional taxes provides a simple and suitable way to overcome the problems that arise from the Keynesian stability condition.

It should finally be mentioned that our approach has a non-negligible side effect, which may appear annoying since it extends the modelling framework, or may be considered welcome because sooner or later such a route has to be taken anyway. The problem is comparable to a topic that within the traditional IS-LM model was first raised by Blinder/Solow (1973): entering this framework is an interest rate on government bonds; hence there must be some agents in the models who receive these payments; hence this income should have a bearing on aggregate demand in the real sector; hence the government bonds should show up explicitly in IS-LM. The bonds, however, cannot be treated 
as exogenously given but, because they are issued to finance the public deficit, they are generally varying over time. The static IS-LM model has therefore to be supplemented by an equation governing the changes in the stock of bonds (or of money, in that case), that is, it becomes a dynamic model.

The specification of the present framework in which taxes are proportional to certain sources of income means that in general the government budget is not balanced. As in Blinder/Solow, an equation has to be added that describes the changes in government bonds or, being in a growth context, in the bond-to-capital ratio. Then, a first consequence presents itself as soon as one wishes to study the effects of exogenous variations in some of the model's parameters, such as the government spending ratio $\gamma_{n}$ or the profit share $h:$ a decision on the underlying equilibrium notion has to be made beforehand.

A natural candidate is, of course, a steady-state growth path. As has been seen in Section 5, a transition from one long-run equilibrium to another requires the government to suitably adjust its tax policy. Such a 'functional finance' would be a new issue in the original Kaleckian frame of analysis. The first point is then whether the government is willing or able at all to undertake this task. Second, even if it is, it would not be very realistic to assume that the government already knows the correct parameters. Third, even if this knowledge and also stability are taken for granted, these processes will very likely take a long time to work out (not least because the stock adjustments themselves will take their time). Convergence may easily take so long that in the meantime this tendency is blotted out by other structural changes in the economy. Consequently, the new steady state would be of less significance than the initial stages of a transition toward it.

These first thoughts and sketchy remarks indicate that the emergence of the bond dynamics in our extended framework would also raise new methodological issues that need to be discussed. On the whole we may conclude that, largely, the challenge of the problem of the Keynesian stability condition may be considered to be mastered, while the solution is traded for new challenges of a different sort, or at a higher theoretical level.

\section{REFERENCES}

Assous, M., Dutt, A.K. (2013): Growth and income distribution with the dynamics of power in labour and goods markets, in: Cambridge Journal of Economics, 37, 1407-1430.

Bhaduri, A., Marglin, S. (1990): Unemployment and the real wage: the economic basis for contesting political ideologies, in: Cambridge Journal of Economics, 14, 375-393.

Blinder, A.S., Solow, R.M. (1973): Does fiscal policy matter?, in: Journal of Public Economics, 2, 319-337. (Reprinted in: Havrilesky, T.M., Boorman, J.T. (eds), 1976, Current Issues in Monetary Theory and Policy, Arlington Heights, IL: AHM Publishing, 112-127.)

Chiarella, C., Flaschel, P., Franke, R. (2005): Foundations for a Disequilibrium Theory of the Business Cycle: Qualitative Analysis and Quantitative Assessment, Cambridge, UK: Cambridge University Press.

Dallery, T. (2007): Kaleckian models of growth and distribution revisited: evaluating their relevance through simulation, Paper presented at the 11th workshop of the Research Network Macroeconomic Policies, Berlin, October.

Dutt, A.K. (1984): Stagnation, income distribution and monopoly power, in: Cambridge Journal of Economics, 8, 25-40.

Franke, R. (2009): Applying the method of simulated moments to estimate a small agent-based asset pricing model, in: Journal of Empirical Finance, 16, 804-815. 
Franke, R. (2015): A simple approach to overcome the problems from the Keynesian stability condition, Working paper, University of Kiel, URL: https://www.gwif.vwl.uni-kiel.de/de/workingpapers-1.

Franke, R., Yanovski, B. (2016): On the long-run equilibrium value of Tobin's average Q, in: European Journal of Economics and Economic Policies: Intervention, 13, 103-113.

Franke, R., Jang, T., Sacht, S. (2015): Moment matching versus Bayesian estimation: backwardlooking behaviour in a New-Keynesian baseline model, in: North American Journal of Economics and Finance, 31(2015), 126-154.

Hein, E., Schoder, C. (2011): Interest rates, distribution and capital accumulation: a post-Kaleckian perspective on the US and Germany, in: International Review of Applied Economics, 25, 693-723.

Jang, T., Sacht, S. (2016): Animal spirits and the business cycle: empirical evidence from moment matching, in: Metroeconomica, 67, 76-113.

Jarsulic, M. (1992): Debt and macro stability, in: Papadimitriou, D.B. (ed.), Profits, Deficits and Instability, London: Macmillan, 317-329.

Lavoie, M. (2010): Surveying short-run and long-run stability issues with the Kaleckian model of growth, in: Setterfield, M. (ed.), Handbook of Alternative Theories of Economic Growth, Cheltenham, UK and Northampton, MA: Edward Elgar, 132-156.

Lavoie, M. (2014): Post-Keynesian Economics: New Foundations, Cheltenham, UK and Northampton, MA: Edward Elgar.

Lee, B.-S., Ingram, B.F. (1991): Simulation estimation of time series models, in: Journal of Econometrics, 47, 197-205.

Lerner, A.P. (1943): Functional finance and the federal debt, in: Social Research, 10, 38-57.

Onaran, Ö., Galanis, G. (2012): Is aggregate demand wage-led or profit-led? National and global effects, ILO Conditions of Work and Employment Series No 40.

Rowthorn, B. (1981): Demand, real wages and economic growth, in: Thames Papers in Political Economy, Autumn, 1-39.

Ryoo, S., Skott, P. (2013): Public debt and full employment in a stock-flow consistent model of a corporate economy, in: Journal of Post Keynesian Economics, 35, 511-527.

Ryoo, S., Skott, P. (2015): Fiscal and monetary policy rules in an unstable economy, Working paper, Adelphi University and University of Massachusetts (forthcoming in Metroeconomica).

Skott, P. (1989): Conflict and Effective Demand in Economic Growth, Cambridge, UK: Cambridge University Press.

Skott, P. (2010): Growth, instability and cycles: Harrodian and Kaleckian models of accumulation and income distribution, in: Setterfield, M. (ed.), Handbook of Alternative Theories of Economic Growth, Cheltenham, UK and Northampton, MA: Edward Elgar, 108-131.

Skott, P. (2012): Theoretical and empirical shortcomings of the Kaleckian investment function, in: Metroeconomica, 63(1), 109-138.

Skott, P., Ryoo, S. (2008): Macroeconomic implications of financialisation, in: Cambridge Journal of Economics, 32, 827-862.

Steindl, J. (1952): Maturity and Stagnation in American Capitalism, Oxford: Basil Blackwell. 


\section{APPENDIX 1}

\section{A1.1 The partial derivatives in equations in (21), (22) and in Table 1}

Let $N_{I S}$ be the numerator of $b_{I S}^{o}$ in $(21)$. Then $\partial c_{b} / \partial \tau_{p}=-\left(1-s_{r}\right)<0$ and:

$$
\begin{array}{lll}
\frac{\partial N_{I S}}{\partial \tau_{p}}=\left(1-s_{r}\right)\left\{\left(1-\tau_{v}\right) u^{n}-\delta-\tau_{c}\left[\left(1-\tau_{v}\right) h u^{n}-\delta-j d^{o}\right]\right\} & \\
\frac{\partial N_{I S}}{\partial \gamma_{n}}=-u^{n}<0 & \frac{\partial c_{b}}{\partial \gamma_{n}}=0 & \frac{\partial c_{b}}{\partial g^{o}}=0 \\
\frac{\partial N_{I S}}{\partial g^{o}}=-1<0 & \frac{\partial c_{b}}{\partial s_{r}}=-\left(1-\tau_{p}\right) \\
\frac{\partial N_{I S}}{\partial s_{r}}=\left(1-\tau_{p}\right)\left\{\left(1-\tau_{c}\right)\left[\left(1-\tau_{v}\right) h u^{n}-\delta\right]+\tau_{c} j d^{o}\right\}>0 & & \frac{\partial c_{b}}{\partial h}=0 . \\
\frac{\partial N_{I S}}{\partial h}=\left(1-\tau_{v}\right)\left(1-\tau_{p}\right)\left[s_{r}+\tau_{c}\left(1-s_{r}\right)\right] u^{n}>0 &
\end{array}
$$

The statement on the reactions of $b_{I S}^{o}$ in the first row of Table 1 follows immediately. With respect to $b_{G D}^{o}$ in (22), where $N_{G D}$ may denote the numerator of the fraction, we have $\partial a_{3} / \partial \tau_{p}=i b^{o}>0$ and:

$$
\begin{array}{lll}
\frac{\partial N_{G D}}{\partial \tau_{p}}=-\left[\left(1-\tau_{v}\right) u^{n}-\delta\right]+\tau_{c}\left[\left(1-\tau_{v}\right) h u^{n}-\delta+j d^{o}\right]<0 & \\
\frac{\partial N_{G D}}{\partial \gamma_{n}}=u^{n}>0 & & \frac{\partial a_{3}}{\partial \gamma_{n}}=0 \\
\frac{\partial N_{G D}}{\partial g^{o}}=0 & \frac{\partial a_{3}}{\partial g^{o}}=b>0 \\
\frac{\partial N_{G D}}{\partial s_{r}}=0 & & \frac{\partial a_{3}}{\partial s_{r}}=0 \\
\frac{\partial N_{G D}}{\partial h}=-\tau_{c}\left(1-\tau_{v}\right)\left(1-\tau_{p}\right) u^{n}<0 & & \frac{\partial a_{3}}{\partial h}=0 .
\end{array}
$$

This establishes the signs of the reactions in the second row of the table.

\section{A1.2 The data sources}

The values of the (gross) profit share $h$, the production tax rate $\tau_{v}$ and the corporate tax rate $\tau_{c}$ are based on quarterly US data for the non-financial corporate business that can be downloaded from the homepage of the Federal Reserve (www.federalreserve.gov); cf. also table S.5.a on p. 147 of the Z.1 Financial Accounts of the United States (Flow of Funds, Balance Sheets, and Integrated Macroeconomic Accounts).

The time series underlying are: gross value added (GVA); consumption of fixed capital (CFC); compensation of employees (CompE), which consists of wages and salaries and employers' social contributions; the taxes on production and imports less subsidies 
(TaxP); the taxes on corporate income (TaxCI), which more precisely are called current taxes on income, wealth, etc. (paid); the rents paid (Rent); and the net interest payments (Int), that is, interest paid minus interest received. From them we obtain:

$$
\begin{aligned}
\tau_{v} & =\text { TaxP } / \text { GVA } \\
h & =(\text { GVA }- \text { TaxP }- \text { CompE }) /(G V A-\text { TaxP }) \\
\tau_{c} & =\text { TaxCI } /(\text { GVA }- \text { TaxP }- \text { CompE }- \text { CFC }- \text { Rent }- \text { Int }),
\end{aligned}
$$

where the denominator of $\tau_{c}$ represents the net profits of the firms, that is, the operating surplus net of depreciation and interest and similar payments.

A major alternative data source is the database fmdata.dat in the zip file fmfp.zip that is provided by Ray Fair on his homepage for working with his macroeconometric model, at http://fairmodel.econ.yale.edu/fp/fp.htm. This is a huge plain text file from which the single time series have to be extracted for further use. Each of them is identified by an acronym. They are explained in chapter 6.5, table A2, of the script Macroeconometric Modeling by R.C. Fair, 11 November 2011, which can be downloaded from http:/fairmodel.econ.yale.edu/ $\mathrm{mmm} 2 . / \mathrm{mm}$.pdf (last accessed July 2015, though the data we used are of an older vintage).

It is particularly convenient that the database contains a quarterly series of the real capital stock (acronym KK) of (essentially) the non-financial corporate business (NFCB). Using the perpetual inventory method, it is based on fixed non-residential investment of this sector, and not total fixed non-residential investment in the economy, which is on average $1 / 0.887=1.127$ times higher (see pp. $184 \mathrm{f}$ of the aforementioned book).

One can then readily compute the time averages of the (annualized) growth rate of this capital stock and the ratio of the real output over the real capital stock. ${ }^{23}$ The inflation rate $\pi$ is obtained from the price deflator of the NFCB output, while the bond rate $i$ in Table 2 is the 3-month treasury bill rate. Regarding the rate of depreciation, the database gives us an average of 6.62 per cent. This may appear unfamiliarly low. ${ }^{24}$ The Fed data actually yield an average ratio $\mathrm{CFC} / \mathrm{GVA}=13.21$ per cent, so that multiplying it by our value 0.90 for the output-capital ratio leads to a depreciation rate in the range of 11.90 per cent. Thus we choose to settle down on $\delta=10$ per cent (though not very much will depend on this).

The value for the loan rate $j$ is lastly derived from the US bank prime loan-middle rate (which is on short-term business loans). It was obtained from Datastream, code FRBKPRM.

23. One had better not use the nominal magnitudes in this ratio because the price deflators of output and capital show different tendencies.

24. It was steadily increasing from 4.59 per cent in 1983 to 9.41 per cent in 2007 . 